\title{
Pengaruh Penambahan Dosis Koagulan Terhadap Parameter Kualitas Air dengan Metode Jartest
}

\section{The Effect of Coagulant Dosage Added on Water Quality Parameters with the Jartest Method}

\author{
Nur Ihda Farikhatin Nisa ${ }^{*}$, Achmad Aminudin ${ }^{2}$ \\ ${ }^{1}$ Program Studi Teknik Kimia, Fakultas Teknik \\ Universitas PGRI Madiun \\ Jl. Auri No. 14-16, Kota Madiun 63117, Indonesia. \\ 2Program Studi Mesin Otomotif, Jurusan Teknik \\ Politeknik Negeri Madiun \\ Jl. Serayu No. 84, Kota Madiun 63133, Indonesia. \\ email: ${ }^{* 1}$ nurihda_fn@unipma.ac.id, ${ }^{2}$ udin@ @nm.ac.id
}

DOI:

10.30595/jrst.v3i2.4500

Histori Artikel:

Diajukan:

27/05/2019

Direvisi:

20/09/2019

Diterima:

25/09/2019

\section{ABSTRAK}

Air merupakan salah satu komponen penting dalam kehidupan manusia ataupun makhluk hidup lainnya. Dengan semakin banyaknya jumlah penduduk, maka kebutuhan akan air bersih juga mengalami peningkatan. Akan tetapi, peningkatan kebutuhan ini tidak diimbangi dengan ketersediaan air bersih yang disebabkan oleh semakin rendahnya kualitas air yang dihasilkan oleh unit instalasi pengolahan air. Oleh karena itu, perlu dilakukan alternatif pengolahan air agar kebutuhan air bersih dapat mencukupi. Salah satu metode pengolahan air bersih yang dapat dilakukan adalah metode Jartest. Penelitian ini bertujuan untuk mengetahui pengaruh penambahan dosis koagulan terhadap parameter kualitas air diantaranya $\mathrm{pH}$, turbidity, TDS dan total hardness dari sampel air sumur Manisrejo Kota Madiun sesudah pengolahan air. Adapun metode penelitian dilakukan melalui tiga tahap yaitu tahap persiapan, tahap analisa instrument dan tahap percobaan. Dimana jenis koagulan yang digunakan adalah Poly Aluminium Chloride (PAC). Dari penelitian yang telah dilakukan diperoleh dosis koagulan PAC yang optimum adalah sebesar $43 \mathrm{mg} / \mathrm{l}$. Kesimpulan yang didapatkan pada penelitian ini yaitu semakin besar dosis koagulan yang ditambahkan pada sampel air tersebut maka semakin kecil nilai $\mathrm{pH}$, nilai turbidity, nilai TDS dan total hardness dari sampel air.

Kata Kunci: koagulan, pengolahan air, jartest, PAC

\begin{abstract}
Water is one of the important components of human life or other living things. With the increasing number of residents, the need for clean water has also increased. However, this increase in demand is not offset by the availability of clean water due to the lower quality of water produced by the water treatment plant. Therefore, it is necessary to do alternative water treatment so that clean water needs can be sufficient. One method of processing clean water that can be done is the Jar test method. This study aims to determine the effect of coagulant dose addition on water quality parameters including $\mathrm{pH}$, turbidity, TDS and total hardness of the Manisrejo City Madiun well water sample after water treatment. The research method is carried out through three stages, namely the preparation stage, the instrument
\end{abstract}


analysis stage and the experimental stage. Where the type of coagulant used is Poly Aluminum Chloride (PAC). From the research that has been done, the optimum PAC coagulant dose is $43 \mathrm{mg} / \mathrm{l}$. The conclusion obtained in this study is that the greater the coagulant dose added to the water sample, the smaller the $\mathrm{pH}$ value, the value of turbidity, the TDS value and the total hardness of the water sample.

Keywords: coagulant, water treatment, jartest, PAC

\section{PENDAHULUAN}

Air merupakan salah satu komponen penting dalam kehidupan manusia ataupun makhluk hidup lainnya. Dengan semakin banyaknya jumlah penduduk, maka kebutuhan akan air bersih juga mengalami peningkatan. Akan tetapi, peningkatan kebutuhan ini tidak diimbangi dengan ketersediaan air bersih yang disebabkan oleh semakin rendahnya kualitas air yang dihasilkan oleh unit instalasi pengolahan air.

Kota madiun memiliki 3 kecamatan dengan jumlah kelurahan sebanyak 27 kelurahan. Salah satu kelurahan di kota ini adalah kelurahan Manisrejo. Di kota ini, seluruh kebutuhan air bersih diperoleh dengan memanfaatkan sumur dalam sebagai satusatunya sumber air baku (Kusumawardani \& Astuti, 2018). Air yang digunakan warga seharihari bisa berasal dari PDAM atau langsung dari sumur yang kualitas airnya tidak sesuai dengan baku mutu yang disyaratkan untuk air minum .

Oleh karena itu, perlu dilakukan alternatif pengolahan air baku menjadi air bersih yang layak untuk dikonsumsi. Metode yang digunakan untuk menghilangkan surfaktan banyak melibatkan berbagi proses baik kimia, fisika maupun biologi (Aygun \& Yilmaz, 2010). Penelitian ini menggunakan metode Jartest yang terdiri dari proses koagulasi, flokulasi dan sedimentasi. Dimana senyawa kimia yang dipakai sebagai koagulan adalah Poly Aluminium Chloride (PAC).

Penelitian ini bertujuan untuk mengetahui pengaruh penambahan dosis koagulan PAC terhadap parameter kualitas air yang terdiri dari parameter $\mathrm{pH}$, turbidity, TDS dan total hardness dari sampel air Manisrejo sesudah proses pengolahan air.

\section{METODE PENELITIAN}

Adapun metode penelitian terdiri dari 3 tahap yaitu tahap persiapan, tahap analisa instrument dan tahap percobaan.

\subsection{Bahan Penelitian}

Bahan yang dipakai pada penelitian ini adalah air sumur di daerah Manisrejo Kota Madiun, PAC sebagai koagulan dan aquadest.

\subsection{Alat yang Digunakan}

Alat yang digunakan diantaranya beaker glass, buret, statif, klem holder, cawan, erlenmeyer, flokulator, gelas ukur, labu ukur, oven, $\mathrm{pH}$ meter, pipet tetes, spatula, stopwatch, TDS meter, timbangan elektrik dan turbidimeter.

\subsection{Prosedur Penelitian \\ 2.3.1. Tahap Persiapan}

Tahap persiapan dilakukan dengan cara mengkalibrasi alat analisa instrument.

a. $\mathrm{pH}$ meter

$\mathrm{pH}$ meter dikalibrasi menggunakan sampel air baku dengan $\mathrm{pH}$ 6,8-7,2 setiap sebelum dan setelah pengukuran $\mathrm{pH}$ dari air sampel. Apabila air baku yang digunakan untuk kalibrasi alat pHnya tidak diantara 6,8-7,2 maka diganti dengan air baku yang baru

\section{b. TDS meter}

TDS meter dikalibrasi dengan mencelupkan elektroda dalam larutan standar (larutan $\mathrm{NaCl} 342 \mathrm{mg} / \mathrm{l}$ ). Apabila hasil pengukuran TDS meter tidak sesuai dengan konsentrasi larutan standar, maka menekan tombol "TEMP" sampai display angka pada alat tersebut berkedip. Kemudian mengubah konsentrasi larutan sesuai dengan standar (menekan tombol "HOLD" atau ON/OFF)

c. Turbidimeter

Turbidimeter dikalibrasi menggunakan sampel larutan standar yang memiliki angka turbiditas 0,01 NTU.

\subsubsection{Tahap Analisa Instrumentasi}

a. Analisa $\mathrm{pH}$

Analisa $\mathrm{pH}$ dilakukan menggunakan alat pH meter. Langkah-langkah yang dilakukan yaitu mencelupkan elektroda $\mathrm{pH}$ meter ke dalam air sampel yang telah dimasukkan ke dalam erlenmeyer dengan volume air sampel $10 \mathrm{ml}$. 
Angka yang tertera pada display $\mathrm{pH}$ meter adalah nilai $\mathrm{pH}$ dari air sampel tersebut. Mengulangi langkah analisa diatas untuk variabel sesudah proses Jartest dengan penambahan koagulan PAC masing-masing sebesar $25 \mathrm{mg} / \mathrm{l} ; 31 \mathrm{mg} / \mathrm{l}$; $37 \mathrm{mg} / \mathrm{l} ; 43 \mathrm{mg} / \mathrm{l} ; 49 \mathrm{mg} / \mathrm{l}$ dan $55 \mathrm{mg} / \mathrm{l}$.

\section{b. Analisa TDS (Total Dissolved Solid)}

Air sampel yang telah dimasukkan ke dalam erlenmeyer dengan volume sebesar $10 \mathrm{ml}$ kemudian diukur nilai TDS nya. Mencelupkan elektroda TDS meter yang telah dikalibrasi ke dalam erlenmeyer, kemudian mencatat angka yang tertera pada alat TDS meter. Mengulangi langkah analisa diatas untuk variabel sesudah proses Jartest dengan penambahan koagulan PAC masing-masing sebesar $25 \mathrm{mg} / \mathrm{l} ; 31 \mathrm{mg} / \mathrm{l}$; $37 \mathrm{mg} / \mathrm{l} ; 43 \mathrm{mg} / \mathrm{l} ; 49 \mathrm{mg} / \mathrm{l}$ dan $55 \mathrm{mg} / \mathrm{l}$.

\section{c. Analisa Turbidity}

Analisa turbidity dilakukan dengan menyambungkan alat pada sumber listrik dan menunggu sampai 15 menit. Memasukkan air sampel ke dalam alat turbidimeter sampai garis batas yang ditentukan pada alat. Membaca nilai turbidity pada display angka. Mengulangi langkah analisa diatas untuk variabel sesudah proses Jartest dengan penambahan koagulan PAC masing-masing sebesar $25 \mathrm{mg} / \mathrm{l} ; 31 \mathrm{mg} / \mathrm{l}$; $37 \mathrm{mg} / \mathrm{l} ; 43 \mathrm{mg} / \mathrm{l} ; 49 \mathrm{mg} / \mathrm{l}$ dan $55 \mathrm{mg} / \mathrm{l}$.

\subsubsection{Tahap Percobaan}

a. Proses Koagulasi

Koagulasi merupakan proses kimia yang dapat digunakan untuk menghilangkan bahan cemaran yang tersuspensi ataupun dalam bentuk koloid (Nurlina, Zahara, Gusrizal \& Kartika, 2015). Faktor yang dapat mempengaruhi proses koagulasi diantaranya sifat fisis maupun sifat kimia dari koloid ataupun koagulan yang digunakan (Herawati, Asti, Ismuyanto, Juliananda \& Hidayati, 2017). Langkah yang dilakukan yaitu dengan memasukkan air sampel ke dalam beaker glass $1000 \mathrm{ml}$ sebanyak 6 buah, kemudian meletakkan ketiga beaker glass ke dalam flokulator. Mengatur agar agilator tidak bergesekan dengan dinding beaker glass lalu menyiapkan koagulan PAC sebanyak $25 \mathrm{mg} ; 31$ $\mathrm{mg} ; 37 \mathrm{mg} ; 43 \mathrm{mg} ; 49 \mathrm{mg}$ dan $55 \mathrm{mg}$. Menyalakan flokulator dengan kecepatan pengadukan $120 \mathrm{rpm}$ dan menunggu hingga kecepatan pengadukan konstan. Setelah kecepatan pengadukan stabil, menambahkan koagulan sesuai dosis yang telah ditentukan.
Dalam penambahan koagulan diusahakan mendekati titik pengaduk. Proses koagulasi dilakukan selama 10 menit dan dihitung tepat setelah penambahan koagulan. Gambaran proses koagulasi ditunjukkan pada Gambar 1 dibawah ini.

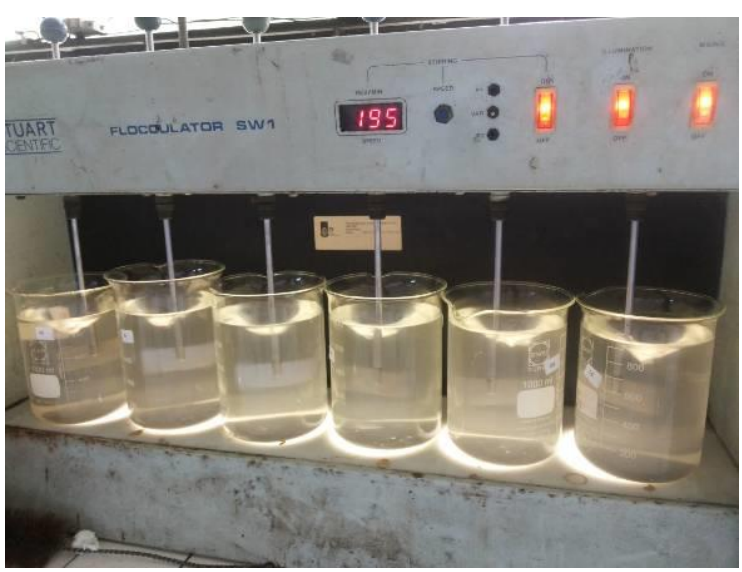

Gambar 1. Proses koagulasi

\section{b. Proses Flokulasi}

Flokulasi adalah metode yang diguanakan untuk membentuk flok yang lebih besar yang merupakan kumpulan flok-flok kecil dari proses koagulasi (Margaretha, Mayasari, Syaiful \& Subroto, 2012). Setelah proses koagulasi selesai selanjutnya menurunkan kecepatan pengadukan dari $120 \mathrm{rpm}$ menjadi 25 rpm. Proses flokulasi dilakukan selama 15 menit dan dihitung tepat setelah proses koagulasi. Setelah proses flokulasi selesai, mematikan agitator dan membiarkan lampu flokulator tetap menyala. Gambaran proses flokulasi dapat dilihat pada Gambar 2.

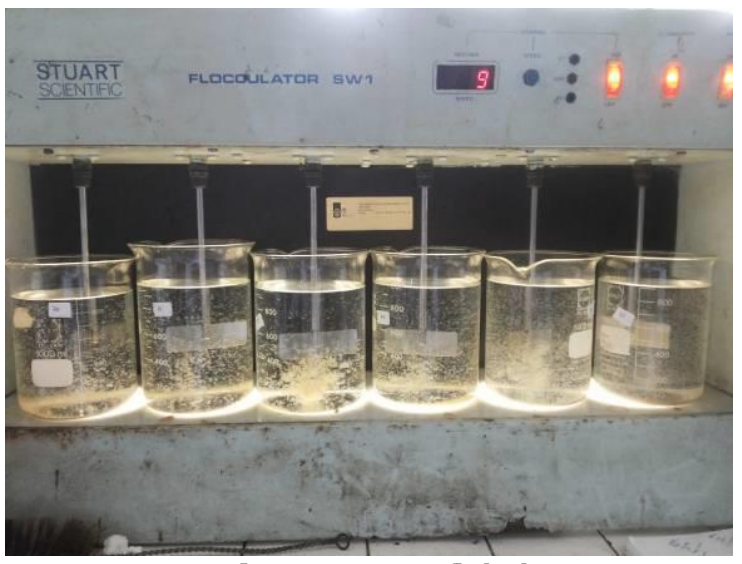

Gambar 2. Proses flokulasi 


\section{d. Proses Sedimentasi}

Proses sedimentasi dimulai setelah proses flokulasi selesai. Beaker glass tetap berada di flokulator dengan lampu menyala agar pembentukan dan sedimentasi flok dapat diamati. Proses sedimentasi dilakukan selama 30 menit dan dihitung tepat ketika agitator berhenti kemudian menghitung volume flok yang mengendap.

\section{HASIL DAN PEMBAHASAN}

\subsection{Analisa Awal Air Sample}

Kualitas air sangat ditentukan oleh banyak parameter diantaranya parameter fisik, kimia dan biologi (Sahu \& Chaudhari, 2013). Hasil analisa awal air sampel dapat dilihat pada Tabel 1 di bawah ini.

Tabel 1. Hasil Analisa Awal Air Sampel

\begin{tabular}{clccc}
\hline No. & Parameter & Satuan & $\begin{array}{c}\text { Baku } \\
\text { Mutu* }\end{array}$ & $\begin{array}{c}\text { Hasil } \\
\text { Analisa }\end{array}$ \\
\hline 1. & pH & & $6,5-8,5$ & 7,69 \\
2. & Turbidity & NTU & 5 & 16,7 \\
3. & TDS & $\mathrm{mg} / \mathrm{l}$ & 500 & 7,28 \\
4. & Total & $\mathrm{Mg} / \mathrm{l}$ & 500 & 135 \\
\hline
\end{tabular}

Dari tabel 1 diatas dapat dilihat bahwa parameter turbidity mempunyai nilai yang melebihi ambang batas persyaratan air minum dalam Peraturan Menteri Kesehatan dengan nomor 492/MENKES/PER/1V/2010. Untuk itu, diperlukan penanganan agar air tersebut memenuhi baku mutu yang disyaratkan (Sabilina, Setiawan \& Afiuddin, 2015)

Dalam penelitian ini tidak semua parameter air sampel akan diteliti pengaruhnya terhadap penambahan dosis koagulan. Adapun parameter-parameter yang akan diteliti dengan metode Jartest diantaranya $\mathrm{pH}$, turbidity, TDS dan total hardness.

\subsection{Pengaruh Dosis Koagulan terhadap pH}

pH merupakan indikator untuk mengetahui tingkat keasaman ataupun basa dari suatu larutan. $\mathrm{pH}$ sangat besar pengaruhnya terhadap proses pengolahan air karena jika pengolahan air tidak terjadi pada $\mathrm{pH}$ optimum akan menyebabkan kualitas air yang dihasilkan rendah (Wardani, Iswanto \& Winarni, 2009). Dimana perubahan $\mathrm{pH}$ pada air dapat menyebabkan perubahan pada bau, rasa maupun warna dari air tersebut. Pengaruh dosis koagulan terhadap nilai $\mathrm{pH}$ ditunjukkan pada Gambar 3 dibawah ini.

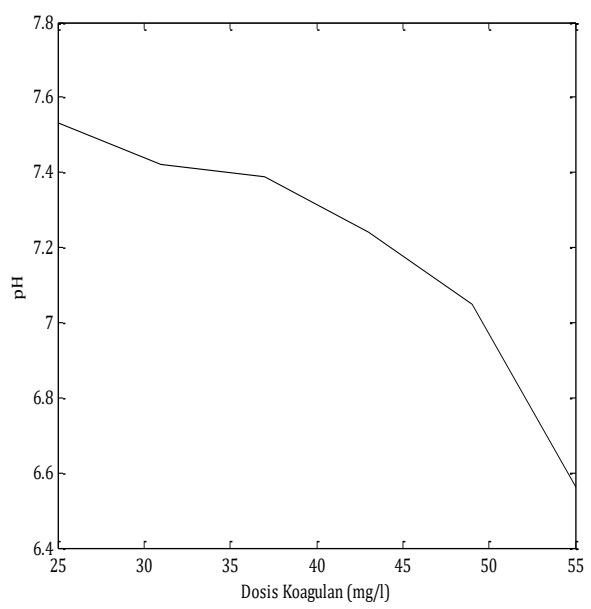

Gambar 3. Pengaruh dosis koagulan terhadap $\mathrm{pH}$

Dari Gambar 3 diatas dapat dilihat bahwa dengan penambahan dosis koagulan PAC $25 \mathrm{mg} / \mathrm{l} ; 31 \mathrm{mg} / \mathrm{l} ; 37 \mathrm{mg} / \mathrm{l} ; 43 \mathrm{mg} / \mathrm{l} ; 49 \mathrm{mg} / \mathrm{l} \mathrm{dan}$ $55 \mathrm{mg} / \mathrm{l}$ terjadi penurunan nilai $\mathrm{pH}$. didapatkan dosis optimum koagulan pada konsentrasi 43 $\mathrm{mg} / \mathrm{l}$. Hal ini disebabkan karena semakin besar dosis koagulan dalam suatu larutan, maka semakin besar juga kandungan ion $\mathrm{H}^{+}$dalam larutan tersebut akibat adanya proses hidrolisa (Rusdi, Sidi \& Pratama, 2014). Peningkatan ion $\mathrm{H}^{+}$menyebabkan larutan cenderung mempunyai $\mathrm{pH}$ rendah (asam). Dimana pemakaian PAC paling efektif antara range $\mathrm{pH}$ 6-9.

\subsection{Pengaruh Dosis Koagulan terhadap Turbidity}

Turbidity atau kekeruhan adalah adanya bahan pencemar yang bisa berupa partikel koloid ataupun suspensi yang dihasilkan dari limbah rumah tangga ataupun limbah industry yang terkandung dalam suatu perairan. Pengaruh dosis koagulan terhadap nilai turbidity pada sampel air ditunjukkan pada Gambar 4. 


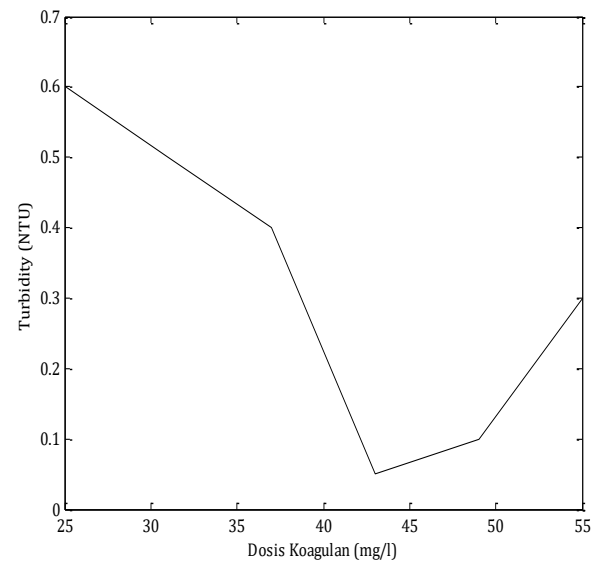

Gambar 4. Pengaruh dosis koagulan terhadap turbidity

Gambar 4 menunjukkan bahwa semakin besar dosis koagulan pada air sampel menyebabkan penurunan nilai turbidity. Dimana dosis optimum koagulan PAC terjadi pada saat $43 \mathrm{mg} / \mathrm{l}$ dengan nilai turbidity paling kecil yaitu sebesar 0,05 NTU. Penambahan dosis koagulan diatas $43 \mathrm{mg} / \mathrm{l}$ justru akan menaikkan nilai turbidy. Hal ini disebabkan karena terjadi gaya tolak menolak diantara partikel yang bermuatan positif sehingga terjadi proses deflokulasi flok yang mengakibatkan larutan menjadi semakin keruh (Margaretha, Mayasari, Syaiful \& Subroto, 2012)(Coniwanti, Mertha \& Eprianie, 2013)

\subsection{Pengaruh Dosis Koagulan terhadap TDS}

Total Dissolved Solids (TDS) adalah parameter yang digunakan untuk mengetahui jumlah kandungan padatan dalam air (Mayasari,2016)(Ginting, Pinem \& Irianty, 2016). Pengaruh dosis koagulan terhadap nilai TDS dapat dilihat pada Gambar 5 .

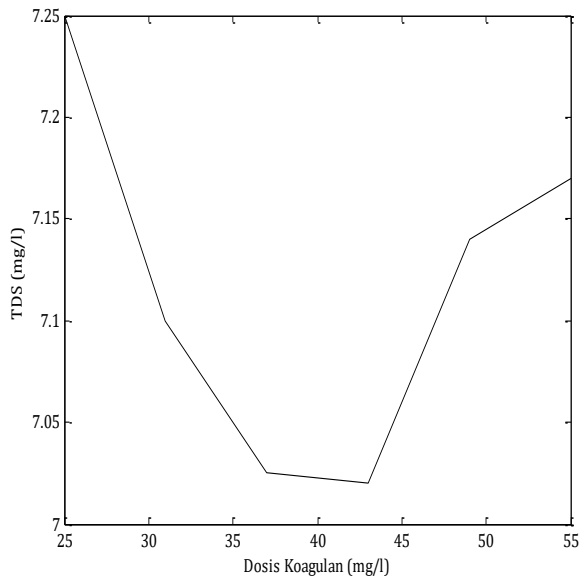

Gambar 5. Pengaruh dosis koagulan terhadap TDS

Dari Gambar 5 di atas dapat dilihat bahwa semakin banyak dosis koagulan yang ditambahkan pada air sampel menyebabkan nilai TDS semakin menurun. Dengan dosis optimum terjadi pada saat konsentrasi koagulan PAC 43 $\mathrm{mg} / \mathrm{l}$ dengan nilai TDS paling kecil yaitu sebesar $7,02 \mathrm{mg} / \mathrm{l}$. Penambahan kadar koagulan yang berlebih dapat membentuk kembali partikel koloid dalam larutan akibat adanya deflokulasi, sehingga kadar TDS naik (Budiman, Wahyudi, Irawan \& Hindarso, 2008).

\subsection{Pengaruh Dosis Koagulan terhadap Total Hardness}

Kesadahan merupakan parameter yang digunakan untuk mengetahui kandungan kation logam bervalensi dua (Mujariah, Abram \& Jura, 2016). Beberapa kation utama penyebab kesadahan di dalam air antara lain $\mathrm{Ca}^{2+}, \mathrm{Mg}^{2+}$, $\mathrm{Sr}^{2+}, \mathrm{Fe}^{2+}$, dan $\mathrm{Mn}^{2+}$. Sedangkan anion utama penyebab kesadahan di dalam air antara lain $\mathrm{HCO}_{3}{ }^{-}, \mathrm{SO}_{4}{ }^{2-}, \mathrm{Cl}^{-}, \mathrm{NO}_{3}{ }^{-}$, dan $\mathrm{SiO}_{3}{ }^{2}$. Pengaruh dosis koagulan terhadap Total Hardness dapat dilihat pada Gambar 6. 


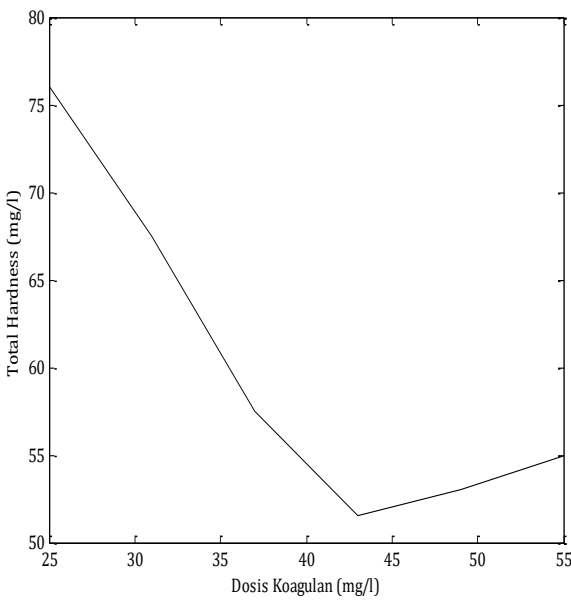

Gambar 6. Pengaruh dosis koagulan terhadap total Hardness

Gambar 6 menunjukkan bahwa penambahan dosis koagulan akan menyebabkan rendahnya nilai kesadahan yang diperoleh. Dimana nilai optimum koagulan terjadi pada saat dosis koagulan $43 \mathrm{mg} / \mathrm{l}$ dengan nilai kesadahan paling rendah sebesar 51,5 mg/l. Akan tetapi, pada saat penambahan dosis koagulan diatas 43 mg/l akan menimbulkan kerak dalam bentuk endapan $\mathrm{CaCO}_{3}$ sehingga dapat menyebabkan korosi pada suhu tinggi (Mujariah, Abram \& Jura, 2017).

\section{KESIMPULAN}

Dari penelitian ini didapatkan kesimpulan bahwa semakin besar dosis koagulan PAC yang ditambahkan pada sampel air Manisrejo Kota Madiun, maka semakin kecil nilai $\mathrm{pH}$, nilai turbidity, nilai TDS dan total hardness dari air sampel.

\section{DAFTAR PUSTAKA}

Aygun, A., Yilmaz, T. (2010). Improvement of Coagulation-Flocculation Process for Treatment of Detergent Wastewaters Using Coagulant Aids. International Journal of Chemical and Environmental Engineering, 1(2), 97-101.

Budiman, A., Wahyudi, C., Irawan, W., Hindarso, H. (2008). Kinerja Koagulan Poly Aluminium Chloride (PAC) Dalam Penjernihan Air Sungai Kalimas Surabaya Menjadi Air Bersih. Widya Teknik, 7, 25-34.

Coniwanti, P., Mertha, I. D., Eprianie, D. (2013).
Pengaruh Beberapa Jenis Koagulan terhadap Pengolahan Limbah Cair Industri Tahu dalam Tinjauannya terhadap Turbidity, TSS dan COD. Jurnal Teknik Kimia, 19(3), 22-30.

Ginting, S. S., Pinem, J. A., Irianty, R. S. (2016). Pengaruh Kombinasi Proses Pretreatment ( Koagulasi-Flokulasi ) Dan Membran Reverse Osmosis Untuk Pengolahan Air Payau. Jom FTEKNIK, 3(2), 1-7.

Herawati, A., Asti, R., Ismuyanto, B., Juliananda, Hidayati, A. S. D. S. N. (2017). Pengaruh pH Dan Dosis Koagulan Ekstrak Biji Kelor Dalam Koagulasi Terhadap Pengurangan Kekeruhan Limbah Cair. Jurnal Rekayasa Bahan Alam Dan Energi Berkelanjutan, 1(1), 25-28.

Kusumawardani, Y., Astuti,W. (2018). Evaluasi Pengelolaan Sistem Penyediaan Air Bersih di PDAM Kota Madiun, Jurnal Neo Teknika, 4(1),1-10.

Margaretha, Mayasari, R., Syaiful \& Subroto. (2012). Pengaruh Kualitas Air Baku Terhadap Dosis Dan Biaya Koagulan Aluminium Sulfat Dan Poly Aluminium Chloride. Teknik Kimia, 18(4), 21-30.

Mayasari, R. (2016).Pengaruh Kualitas Air Baku terhadap Jenis dan Dosis Koagulan, Integrasi, 1(2),45-56.

Mujariah, M., Abram, P. H., Jura, M. R. (2017). Penggunaan Gel Lidah Buaya (Aloe vera) Sebagai Koagulan Alami Dalam Penjernihan Air Sumur Di Desa Sausu Tambu Kecamatan Sausu. Jurnal Akademika Kimia, 5(1), 16-22.

Nurlina, Zahara, T.A., Gusrizal, Kartika, I.D. (2015).Efektivitas Penggunaan Tawas dan Karbon Aktif pada Pengolahan Limbah Cair Industri Tahu. Prosiding SEMIRATA, 690699.

Rachmawati, S. W., Bambang, I., \& Winarni. (2009). Pengaruh pH pada Proses Koagulasi dengan Koagulan Aluminium Sulfat dan Ferri Klorida. Jurnal Teknologi Lingkungan, 5(2), 40-45. 
Rusdi, Sidi, T. B. P., Pratama, R. (2014). Pengaruh Konsentrasi dan Waktu Pengendapan Biji Kelor terhadap pH, Kekeruhan, dan Warna Air Waduk Krenceng. Jurnal Integrasi Proses, 5(1), 46-50.

Sabilina, P. E., Setiawan, A., Afiuddin, A. E. (2015). Studi Penggunaan Dosis Koagulan PAC ( Poly Aluminium Chloride ) dan Flokulan
Polymer Anionic Pada Pengolahan Limbah Cair Industri Tahu. Conference Proceeding on Waste Treatment Technology, 183-188.

Sahu, O.P., Chaudhari, P.K. (2013). Review on Chemical treatment of Industrial Waste Water. Journal Applied Sciences Environmental Management, 17(2), 241257. 